\title{
Chance Finding of Proteinuria Leads to the Diagnosis of ANCA Associated Vasculitis
}

\author{
Hiroshi Okamoto*, Tadashi Sakurai, Mariko Kitahama, Yumi Koseki, Chihiro Terai and \\ Hisashi Yamanaka
}

Institute of Rheumatology, Tokyo Women's Medical University, Tokyo, 162-0054, Japan

\begin{abstract}
Microscopic polyangiitis (MPA) was recognised with a high early mortality rate and the renal involvement was characterised by segmental necrotizing glomerulonephritis with high positivity of antineutrophil cytoplasmic antibody (ANCA) and a broad spectrum of signs and symptoms including fever and malaise. We reported here a woman with ANCA associated with MPA diagnosed by a chance finding of proteinuria. To the best of our knowledge, early diagnosis of this disorder only by the presence of proteinuria has not been reported previously in the English literature.
\end{abstract}

\section{INTRODUCTION}

Microscopic polyangiitis (MPA) was recognised with a high early mortality rate and the renal involvement characterised by segmental necrotising glomerulonephritis and MPA is now defined as a systemic necrotizing vasculitis that affects small-sized vessels with high positivity of antineutrophil cytoplasmic antibody (ANCA) [1]. Patients with ANCAassociated MPA can present a broad spectrum of signs and symptoms including fever and malaise. We reported here a woman with ANCA associated with MPA, diagnosed by a chance finding of proteinuria. To the best of our knowledge, early diagnosis of this disorder only by the presence of proteinuria has not been reported previously in the English literature.

A 62-yr-old Japanese woman was admitted to one of our affiliated hospitals on November 1, 2004 for the regular health check-up with no symptoms. Her past medical history was unremarkable and the regular health check-up performed one year ago showed no findings including urinalysis without proteinuria. On physical examination, the patient had no remarkable physical signs with the following vital signs: blood pressure $124 / 70 \mathrm{~mm} \mathrm{Hg}$, regular pulse $78 / \mathrm{min}$, temperature $36.5^{\circ} \mathrm{C}$, and respiratory rate $20 / \mathrm{min}$. The lungs were clear, the cardiac examination was normal, and there was no peripheral edema. The abdomen was nontender; hepatosplenomegaly was not present. The neurologic examination was unremarkable. The laboratory test results were: haemoglobin $12.4 \mathrm{~g} / \mathrm{dl}$, haematocrit $37 \%$, white blood cell count $6,500 / \mu 1$ with $69 \%$ neutrophils, $25 \%$ lymphocytes, $3 \%$ monocytes and $3 \%$ eosinophils, platelet count $225,000 / \mu 1$, sedimentation rate $12 \mathrm{~mm} / \mathrm{h}$, fasting blood sugar $89 \mathrm{mg} / \mathrm{dl}$, blood urea nitrogen $23.3 \mathrm{mg} / \mathrm{dl}$, creatinine $0.9 \mathrm{mg} / \mathrm{dl}$, sodium $135 \mathrm{mmol} / \mathrm{l}$, and potassium $4.5 \mathrm{mmol} / \mathrm{l}$. Blood transaminases were within normal range. Urinalysis showed protein $(2+)$ and no glucose.

\footnotetext{
*Address correspondence to this author at the Institute of Rheumatology, Tokyo Women's Medical University, 10-22 Kawada-cho, Shinjuku, Tokyo 162-0054, Japan; Tel: +81-3-5269-1725; Fax: +81-3-5269-1726;

E-mail: hokamoto@ior.twmu.ac.jp
}

Urine microscopy was significant for 20-30 red blood cells/high power field 10-20 white blood cells/high power field, and 5-6 squamous epithelial cells/high power field. As she had no proteinuria by the regular check-up last year, urinalysis was conducted and found proteinuria (2+) again. Thus, myeloperoxidase-anti-neutrophil cytoplasmic antibody (MPO-ANCA) titer was examined in her blood and found that MPO-ANCA was positive (162EU). Then, this patient was admitted to our hospital on December 13, 2004 for further investigation of ANCA associated MPA. Proteinuria was quantified as $279 \mathrm{mg} / 24 \mathrm{~h}$ and $\mathrm{Ccr} 58 \mathrm{ml} / \mathrm{minutes}$. Immunologic workup revealed serum complement levels (C3 and $\mathrm{C4}$ ) within normal range, negative anti-nuclear antibody and normal anti-double-stranded DNA. MPO-ANCA was $172 \mathrm{EU}$. The serum creatinine level was $0.9 \mathrm{mg} / \mathrm{dl}$, and the blood urea nitrogen was $20 \mathrm{mg} / \mathrm{dl}$. Renal biopsy was performed and showed focal necrotizing crescentic glomerulonephritis, involving more than half of the glomeruli (Fig. 1). There was a marginal interstitial infiltrate consisting of lymphocytes and neutrophils. Small vessels showed fibrotic thickness and marginal levels of transmural infiltration. Immunofluorescence revealed no deposition of $\mathrm{IgG}$, $\operatorname{IgM}, \operatorname{IgA}$ and $\mathrm{C} 3$ in glomeruli. The patient was diagnosed with MPA on the basis of crescentic necrotising glomerulonephritis and vasculitis on renal biopsy along with MPOANCA positivity. She was treated with methyl-prednisolone pulse therapy $(1 \mathrm{mg} / \mathrm{kg})$ followed by oral prednisolone 40 $\mathrm{mg}$ /day and cyclophophamide $(50 \mathrm{mg} /$ day). No serious side effects of the treatment were observed, and 3-weeks after the treatment, her MPO-ANCA level was improved from 172 to $48 \mathrm{EU}$ and urinalysis revealed no proteinuria. The patient has been followed for more than 3-years to date, corticosteroid was gradually tapered to $8 \mathrm{mg} /$ day and cyclophosphamide $(25 \mathrm{mg} /$ day) was continued as maintenance therapy, and no indications of relapse such as proteinuria or elevation of serum creatinine and MPO-ANCA are apparent so far.

MPA is defined as necrotising vasculitis affecting small vessels (capillaries, venules, or arterioles) with few or no immune deposits (pauci-immune). Several characteristic fea- 

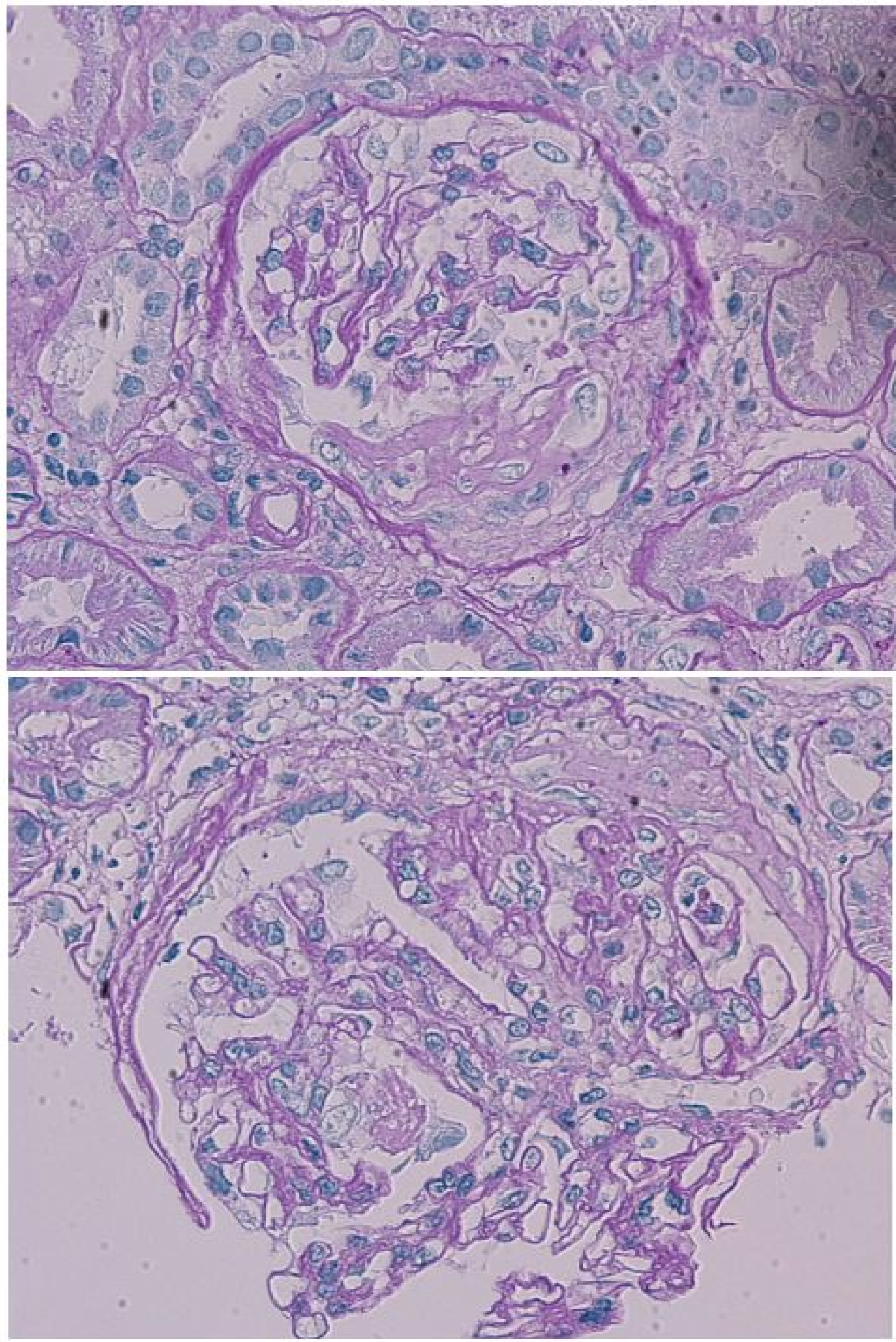

Fig. (1). Glomeruli contain crescentic cell proliferation. (Periodic acid Schiff stain; original magnification $\times 400$ ). 
tures of MPA include pauci-immune focal necrotizing crescentic glomerulonephritis, pulmonary capillaritis, and circulating MPO-ANCA, and it sometimes involves the cutaneous, musculoskeletal, gastrointestinal, and neurologic systems [2-4]. About $60 \%$ of microscopic polyangiitis patients have MPO-ANCA and 30\% have proteinase 3 ANCA [4]. The prognosis of the disease can be improved, if the condition is recognised early and treated with corticosteroids and cytotoxic agents including cyclophosphamide, which induce remission in approximately $80 \%$ of patients. It has been reviewed that diagnosis of MPA is usually preceded by a prodromal phase of several months of constitutional symptoms, including polymyalgia [5].

In summary, the presented patient appeared with chance findings of proteinuria, as an initial clinical sign, indicative of vasculitis in small vessels. Early recognition and treatment of this disease may be important for preventing the development of life-threatening organ damage including end stage renal failure, thereby protecting quality of life and survival of patients with MPA. The presence of ANCA was associated with renal involvement and pulmonary haemorrhage, and to a lesser extent with vasculitis of the skin and mononeuritis multiplex [6]. Although rare, proteinuria may indicate the presence of MPA, hence early testing for ANCA may be warranted to exclude or support this possibility.

\section{REFERENCES}

[1] Lhote F, Cohen P, Genereau T, Guillevin L. Microscopic polyangiitis: Clinical aspects and treatment. Ann Med Intern 1996; 147: 165-77.

[2] Jennette JC, Falk RJ. Small-vessel vasculitis. N Engl J Med 1997; 337: 1512-23.

[3] Seo P, Stone JH. The antineutrophil cytoplasmic antibodyassociated vasculitides. Am J Med 2004; 117: 39-50.

[4] Bosch X, Guilabert A, Font J. Antineutrophil cytoplasmic antibodies. Lancet 2006; 368: 404-18.

[5] Jayne D. Challenges in the management of microscopic polyangiitis: past, present and future. Curr Opin Rheumatol 2008; 20: 3-9.

[6] Sinico RA, Di Toma L, Maggiore U, et al. Renal involvement in Churg-Strauss syndrome. Am J Kidney Dis 2006; 47: 770-9

(C) Okamoto et al.; Licensee Bentham Open.

This is an open access article licensed under the terms of the Creative Commons Attribution Non-Commercial License (http://creativecommons.org/licenses/ by-nc/3.0/) which permits unrestricted, non-commercial use, distribution and reproduction in any medium, provided the work is properly cited. 